Meta

Journal des traducteurs

Translators' Journal

\title{
What Skills Do Student Interpreters Need to Learn in Sight Translation Training?
}

\section{Jieun Lee}

Volume 57, numéro 3, septembre 2012

URI : https://id.erudit.org/iderudit/1017087ar

DOI : https://doi.org/10.7202/1017087ar

Aller au sommaire du numéro

Éditeur(s)

Les Presses de l’Université de Montréal

ISSN

0026-0452 (imprimé)

1492-1421 (numérique)

Découvrir la revue

Citer cet article

Lee, J. (2012). What Skills Do Student Interpreters Need to Learn in Sight Translation Training? Meta, 57(3), 694-714. https://doi.org/10.7202/1017087ar

\section{Résumé de l'article}

Bien que la traduction à vue soit largement enseignée dans le cadre de cours d'interprétation et très utilisée sur le terrain, elle a été peu étudiée. Le présent article expose les résultats préliminaires d'une étude pilote qui a comparé les traductions à vue de six étudiants en interprétation et de trois interprètes professionnels d'un texte anglais en coréen, leur langue maternelle. Il examine leurs performances de traduction à vue en termes de précision, d'expression dans la langue cible et de qualité du débit. Les résultats indiquent que les étudiants ont besoin de développer davantage leurs compétences de lecture afin de comprendre plus précisément le texte source et de faire la distinction entre idées principales et idées secondaires. L'analyse des données révèle également qu'ils doivent faire des efforts délibérés pour se distancier de la forme de la langue source et pour développer des compétences en traduction afin d'éviter les traductions littérales. Ces constatations ont des conséquences pour la formation à la traduction à vue. L'article examine l'usage de concision en tant que méthode efficace permettant d'améliorer le débit et la qualité du discours cible. Enfin, il recommande que davantage d'études soient réalisées sur cet élément de formation en interprétation.
Ce document est protégé par la loi sur le droit d'auteur. L'utilisation des services d'Érudit (y compris la reproduction) est assujettie à sa politique d'utilisation que vous pouvez consulter en ligne.

https://apropos.erudit.org/fr/usagers/politique-dutilisation/ 


\title{
What Skills Do Student Interpreters Need to Learn in Sight Translation Training?
}

\author{
JIEUN LEE \\ Ewha Womans University, Seoul, Republic of Korea \\ jeun.lee@ewha.ac.kr
}

\begin{abstract}
RÉSUMÉ
Bien que la traduction à vue soit largement enseignée dans le cadre de cours d'interprétation et très utilisée sur le terrain, elle a été peu étudiée. Le présent article expose les résultats préliminaires d'une étude pilote qui a comparé les traductions à vue de six étudiants en interprétation et de trois interprètes professionnels d'un texte anglais en coréen, leur langue maternelle. Il examine leurs performances de traduction à vue en termes de précision, d'expression dans la langue cible et de qualité du débit. Les résultats indiquent que les étudiants ont besoin de développer davantage leurs compétences de lecture afin de comprendre plus précisément le texte source et de faire la distinction entre idées principales et idées secondaires. L'analyse des données révèle également qu'ils doivent faire des efforts délibérés pour se distancier de la forme de la langue source et pour développer des compétences en traduction afin d'éviter les traductions littérales. Ces constatations ont des conséquences pour la formation à la traduction à vue. L'article examine l'usage de concision en tant que méthode efficace permettant d'améliorer le débit et la qualité du discours cible. Enfin, il recommande que davantage d'études soient réalisées sur cet élément de formation en interprétation.
\end{abstract}

\begin{abstract}
Although sight translation is widely taught in interpreter education and practicsed in the field, there has been a dearth of studies on sight translation. This paper presents the preliminary findings of a pilot study comparing six student interpreters and three professional interpreters' sight translation of an English speech text into Korean, which is their A language. This paper examines their sight translation performances in terms of accuracy, target language expressions and delivery qualities. The results indicate that student interpreters need to further develop their reading skills to accurately understand the source text and distinguish key ideas from ancillary ideas. The data analysis also reveals that student interpreters need to make conscious efforts to distance themselves from the source language form and develop translation skills to avoid literal translations. These findings have pedagogical implications for sight translation training. This paper discusses condensation strategy as an effective method to enhance delivery and target language qualities. Finally, this paper calls for further research on this under-researched component in the interpreting curriculum.
\end{abstract}

\section{MOTS-CLÉS/KEYWORDS}

traduction à vue, compétences, stratégies, étudiants en interprétation, interprètes professionnels

sight translation, skills, strategy, student interpreters, professional interpreters 


\section{Introduction}

In this paper, the term sight translation (henceforth, ST) refers to the oral translation of a written text. In ST, the source text is a written text as in written translation, while the target text is an oral text as in interpreting. ST may be used in various settings. The interpreter may sight-translate while listening to the speaker's live speech. This is a special mode of simultaneous interpreting (henceforth, SI), which is termed "simultaneous interpreting with text" (Pöchhacker 2004: 19). It is common in conference interpreting settings, which require the interpreter to keep up with the source speech rate. In some non-conference interpreting settings, however, there is no audio input, and the interpreter deals with written source texts only. The discussion in this paper is limited to this type of ST, which is delivered at the interpreter's own pace. Unrehearsed ST may be distinguished from rehearsed ST (Lambert 2004). It is often the case that the interpreter is allowed some preparation time to read the text before the task (rehearsed ST), but it is also possible that the interpreter has to sight-translate on the spot without preparation (unrehearsed ST).

ST requires rapid text analysis, rapid conversion of information from one language to another while avoiding word for word translation, and public speaking techniques (Weber 1990: 50). Reading may be self-paced, but ST delivery speed may not be entirely at the discretion of the interpreter (Brady 1989: 142). Angelelli states that ST should sound as if the interpreter were reading a document in the target language, which implies smooth delivery devoid of hesitations and pauses (Angelelli 1999: 27). Because of time stress and the oral nature of the task, ST appears to have more in common with interpreting than with translation (Brady 1989: 143; Lambert 2004: 298). However, ST is distinct from SI and consecutive interpreting (henceforth, $\mathrm{CI}$ ) in that source language information is presented visually, and the message is processed differently (Agrifoglio 2004: 49). Because of the constant visibility of the source text, listening comprehension ability is not needed in ST. Viezzi's works (1989; 1990) pointed to lower information retention rates after ST than SI and CI, which suggest that memory may not be engaged very vigorously in ST. Based on such empirical evidence, Viezzi $(1989 ; 1990)$ argued that ST processing is not parallel with SI and CI, and that the interpreter may not process and store the incoming information during ST in the same manner as in SI or CI.

As reading and target language production take place concurrently in ST, the interpreter needs to read the source text while thinking of its translation (Weber 1990: 46). Moreover, in order to produce smooth oral renditions, the interpreter may have to read ahead to identify key words and units of translation while planning target language expressions (Agrifoglio 2004: 54). The interpreter may also need to store some information in short-term memory until she reads enough information from the source text to reformulate in the target language. When sentences are long and complex, this may require extra processing efforts on the part of the interpreter. The greater the syntactic difference between the source language and target language, the greater the challenge to the interpreter to coordinate reading and smooth target language production. This intermodality in ST, namely the written source text and the oral target text, may require some specific skills and strategies, but they have so far not been thoroughly examined in the existing literature. ${ }^{1}$ 
The visual input may relieve listening efforts and memory efforts in ST, but may also cause interference in target text production (Martin 1993; Agrifoglio 2004). Therefore, avoiding literal translation is considered to be an important ST skill (Martin 1993: 399; Weber 1990:50). Agrifoglio's study (2004) supports such claims: she examined six professional interpreters' performance in three different modes of interpreting - SI, CI and ST - and found more expression problems in ST than in other modes of interpreting. Most of the target language errors were due to syntactic or grammatical mistakes, including subject verb disagreement. The prevalence of this error type points to coordination problems and short term memory problems. ${ }^{2}$ Based on such findings, Agrifoglio aptly argues that the main difficulty of ST lies in the smooth coordination of the reading, memory and production efforts while managing visual interference from the source language (Agrifoglio 2004: 47).

Despite such challenges in ST, the accuracy of ST is higher than that of other modes of interpreting (see Lambert 2004 and Agrifoglio 2004). Dragsted and Hansen's study (2007) also suggests that ST is more accurate than written translation. Dragsted and Hansen (2007) analysed two translators' ST and written translation and two interpreters' ST outputs. Given that these studies drew on professional interpreters and translators, it remains to be seen whether similar results may be found in student interpreters' ST performances. Student interpreters, who have yet to reach the level of professional proficiency, are likely to have coordination problems in ST. However, in a study based on the responses of 22 student interpreters, Ivars (2008) sought to identify causes of translation problems and strategies, and found that the student interpreters considered source text comprehension problems as the primary cause of translation problems in ST (Ivars 2008: 92). Finding target language equivalents was the second major cause of difficulty according to the student respondents (Ivars 2008: 92). Given that source text comprehension problems may lead to deviations from the original message, students' ST target texts may contain inaccuracies. It has not been documented in the literature whether the primary challenge in ST is associated with comprehension problems, translation competence or delivery, and whether it is viewed differently by student interpreters and professional interpreters.

ST is a part of interpreter training since it is considered effective in raising students' awareness of syntactic and stylistic differences between source language and target language (Martin 1993: 400; Viaggio 1995: 34-35). ST is useful in developing oral skills and language transfer skills through syntactically restructuring and paraphrasing of the source text (Ilg and Lambert 1996: 73). However, despite its importance in the field and in interpreter training, ST has not attracted sufficient scholarly attention in the existing literature on interpreting and interpreter training. Only a handful of studies have focused on ST training, with an emphasis on European language pairs (e.g., Weber 1990; Martin 1993; Moser-Mercer 1995; Ilg and Lambert 1996; Agrifoglio 2004). In the absence of sufficient knowledge on what constitutes proficiency in ST, research on student interpreters' ST performances in comparison with professional interpreters' performances may yield useful information for ST theory and practice. 


\section{The study}

This study, which is partly motivated by the author's desire as a trainer to enhance her own ST teaching methodology, aims to compare students' and professional interpreters' ST performance with a view to identifying the skills possessed by professionals, but not found in student interpreters' ST outputs. By examining professional conference interpreters' and student interpreters' sight translation performances in terms of accuracy, target language expressions and delivery qualities, this paper seeks to focus on qualitative differences between the two interpreter groups, which can be stressed in ST classroom teaching. Given the dearth of literature on ST research and training, such a scholarly investigation on ST performances of both student interpreters and professional interpreters may provide a useful guide to formulate curricula capable of helping student interpreters to acquire these skills and reach professional proficiency.

\subsection{The subjects}

Six student interpreters and three professional interpreters whose A language is Korean and B language is English participated in this pilot study. Of the nine subjects, seven were based in Australia and two professional interpreters were in Korea when the data was collected. (See Table 1 below).

The students were postgraduate interpreting students in Sydney. Three student interpreters (S1, S2, and S3) had studied interpreting for one year and practiced ST during their one-year training period. The other three (S4, S5, and S6) finished the first year course and proceeded to conference interpreting training which included SI with/without texts. These three students had completed their second year course at the time of data collection. It was not possible to recruit a sufficient number of participants from the same cohorts, and in this study, these six students are referred to as student interpreters.

All three professional interpreters were trained conference interpreters, but their training institution, competence and professional experiences varied. Because of limited availability, only three professional interpreters participated in this pilot study. Their professional experience was noted in terms of the number of years as well as the number of conferences or interpreting events with which they had been engaged professionally (see Table 1). Of the three professional interpreters, P2 was the most experienced interpreter with approximately 1,500 conference interpreting experiences, while P3 had interpreted at over 650 conferences. P1 had limited conference interpreting experience with less than 50 conferences. Individual differences in terms of interpreting competence and ST proficiency, both in the student interpreter group and the professional interpreter group, may pose some limitations on the interpretation of the data. However, inter-subject variability, namely "differences between individual interpreters in terms of talent, training, experience, and working methods" (Gile 1994: 42) is deemed inevitable even in a group of interpreters with similar backgrounds (see Lamberger-Felber 2003). 
TABLE 1

The Profile of the Subjects

\begin{tabular}{|c|c|c|c|c|}
\hline ID & Sex & Age group & $\begin{array}{c}\text { Interpreter training } \\
\text { at MA level }\end{array}$ & $\begin{array}{c}\text { Professional interpreting } \\
\text { experience }\end{array}$ \\
\hline S1 & $\mathrm{M}$ & $30 \mathrm{~s}$ & 1 year & NA \\
\hline S2 & $\mathrm{F}$ & $30 \mathrm{~s}$ & 1 year & NA \\
\hline S3 & $\mathrm{F}$ & $20 \mathrm{~s}$ & 1 year & NA \\
\hline S4 & $\mathrm{F}$ & $20 \mathrm{~s}$ & 2 years & NA \\
\hline S5 & $\mathrm{F}$ & $20 \mathrm{~s}$ & 2 years & NA \\
\hline S6 & $\mathrm{F}$ & $20 \mathrm{~s}$ & 2 years & NA \\
\hline P1 & $\mathrm{F}$ & $20 \mathrm{~s}$ & 2 years & 1.5 years (under 50 conferences) \\
\hline P2 & $\mathrm{F}$ & $50 \mathrm{~s}$ & 2 years & 14 years (approx. 1,500 conferences) \\
\hline P3 & $\mathrm{F}$ & $30 \mathrm{~s}$ & 2 years & 8 years (approx. 650 conferences) \\
\hline
\end{tabular}

\subsection{The procedure}

The subjects were asked to sight-translate two English texts into Korean under different conditions. This paper presents the findings from the analysis of ST of the first text, which is an extract from a speech delivered by Al Gore when he was awarded the Nobel Peace Prize in 2007 (see Appendix I). ${ }^{3}$ The source text was an authentic text which was not edited for this experiment. This text was chosen because interpreters frequently deal with speeches, and thus student interpreters as well as professional interpreters were expected to be familiar with this text type.

The subjects were briefed about the procedures and were instructed on what to do step by step. They were informed about the speaker and the context in which the speech was delivered. They were given six minutes for reading the source text of 600 words. ${ }^{4}$ They were provided with pencils and pens to mark on the source text during the reading stage. Those who had not finished reading the whole text in the limited time were asked to mark at which point they stopped reading before sight translating the text. Upon completion of the ST task, they were asked to highlight the parts of the text that caused problems, such as comprehension and target language expression problems. The highlighted parts in the source texts, which indicated perceived difficulties of the subjects, were compared with errors in actual performance transcripts. The subjects were required to complete a questionnaire consisting of multiple choice questions that inquired about their perception of their own performance, the difficulty of the text, their familiarity of the text and the topic, and reading time.

Each subject performed the ST tasks under the supervision of the researcher. Their ST was recorded on a digital voice recorder and was later transcribed by the researcher for analysis. For detailed analysis of the features of the translated texts, silent pauses, fillers, false starts, self-corrections and other grammatical disfluencies were noted in the transcripts. The numbers of inaccuracies and disfluency markers were also counted.

The subjects' ST performances are analysed in the following sections. Firstly, their reading speed is discussed. Then their ST output qualities are analysed, mainly in terms of three criteria - delivery, accuracy and target language qualities - following Lee's (2008) CI assessment criteria. Three raters, including the author, were 
engaged in judging the accuracy and TL expression problems. These raters were interpreters and interpreter trainers themselves.

\subsection{The findings}

\subsubsection{Reading}

Reading is a very complex information processing activity. Reading proficiency requires capabilities to exploit cognitive and other resources (Koda 2005: 204). This section focuses on source text reading speed only. It has to be noted that reading speed itself may not determine the quality of reading, but it may be a good indicator of reading skills. The reading rate may be influenced by such factors as unfamiliar words, suprasentential factors, conceptual difficulties, and the general knowledge of the reader (Nickerson 1981: 273). Vocabulary knowledge and background knowledge, including general knowledge and domain knowledge, are considered important factors that influence reading comprehension (Koda 2005; Miller 2005). However, these key notions lack clear definitions based on theoretical underpinnings and are not easily examined directly (Miller 2005). In ST, reading comprehension may be indirectly examined through the accuracy of the translated texts, as is discussed below.

The comparison of student interpreters and professional interpreters revealed a significant difference. Five students did not read the whole source text within the six minutes' reading time, whereas all three professional interpreters finished reading the whole text, and responded in the questionnaire that they had time to read the text and ponder some translation issues. A student interpreter (S6) responded that she barely finished reading. The other five student interpreters stated that they did not finish reading the source text during the limited reading time. These five student interpreters read between 322 words and 492 words during six minutes (see Table 2). The five student interpreters who did not finish reading the whole text read 67.1 words per minute on average. The four subjects who finished reading the source text within the given time had an average reading speed of 100 words per minute (wpm) or higher. Since it was not expected that some students would not finish reading the source text, the exact reading speed was not recorded. S2 was the slowest reader, reading only 322 of the 600 words during the six minutes' time. In other words, she barely read more than half of the text by the time she started ST. Since it was assumed that more processing efforts may be needed when the interpreter had not read the source text before, good reading speed coupled with good comprehension would clearly facilitate their ST task.

TABLE 2

Reading Speed

\begin{tabular}{|c|c|c|}
\hline ID & Number of words read & $\begin{array}{c}\text { Average reading speed } \\
\text { (words per minute) }\end{array}$ \\
\hline S1 & 414 words & $69 \mathrm{wpm}$ \\
\hline S2 & 322 words & $53.7 \mathrm{wpm}$ \\
\hline S3 & 357 words & $58.5 \mathrm{wpm}$ \\
\hline S4 & 434 words & $72.3 \mathrm{wpm}$ \\
\hline S5 & 492 words & $82 \mathrm{wpm}$ \\
\hline S6 & 600 words & $100 \mathrm{wpm}$ or over \\
\hline
\end{tabular}




\begin{tabular}{|l|l|l|}
\hline P1 & 600 words & 100 wpm or over \\
\hline P2 & 600 words & 100 wpm or over \\
\hline P3 & 600 words & 100 wpm or over \\
\hline
\end{tabular}

According to the feedback provided by the subjects in the questionnaire, only S3 found the topic of the source text unfamiliar while all the other subjects found the topic as well as the speech text type familiar. Since most of the subjects found the topic relatively familiar, their slow reading speed may have resulted from the perceived difficulty of the text and the tasks they were supposed to carry out after the reading, rather than from any lack of familiarity with the text type and the topic. The slower-than-expected reading rate in the student interpreter group may be because English is their B language (L2) and these students' reading may not be comparable to their $\mathrm{L} 1$ reading proficiency. It may also mean that the students tended to read carefully because they had to reproduce the whole message in the target language in ST, which is not generally required in reading comprehension assessments. Reading time and effort may be determined by the purpose of reading. The results support the observation that reading for translation tends to be slower than reading for comprehension, and experienced translators read faster than inexperienced ones (Jakobsen and Jensen 2008, cited in Pym 2009).

As for the failure to read the source text, most of the student interpreters responded that they failed to manage time efficiently while resolving source text comprehension difficulties. Such responses suggest that the student interpreters may not have developed reading strategies to scan the whole text to understand the overall structure of the source text and identify important information rather than getting stuck on difficult words or sentences (Liu, Shallert et al. 2004: 21; Liu 2008: 174). The student interpreters' slow reading may also have been due to their tendency to pay attention to individual words or phrases and focus on unfamiliar words. The literature indicates that efficient readers tend to use the top-down strategy, paying more attention to the meaning of a whole passage using the top-down strategy while poor readers concentrate on individual words using the bottom-up strategy (Carrell 1989; Block 1992; Davis and Bistodeau 1993). In other words, less proficient readers concentrate on decoding while proficient readers are predominantly involved with conceptual processing (Koda 2005: 210, 219). Experts tend to gloss over unknown words and search the context for an explanation (Moser-Mercer 1997: 257). Furthermore, succesful readers may combine top-down and bottom-up reading, effectively compensating for deficiences in bottom-up reading, and vice versa (Stanovich 1980, cited by Cohen 1990: 86). It is also known that experts are better at selecting more important idea units over less important ones, thus reducing the amount of effort spent on processing less relevant information (Liu, Shallert et al. 2004: 21). Further research needs to be conducted for us to fully grasp what reading comprehension means, how it interacts with translation and interpreting, and what reading skills interpreters need to carry out ST. Nevertheless it seems clear that because interpreters often have little time for reading the source text for ST, student interpreters need to develop good reading skills in order to comprehend the source text quickly. The difference between the student interpreter group and the professional interpreter group in reading speed point to the need for further training to develop student interpreters' reading skills and strategies. 


\subsubsection{Delivery}

This section examines only delivery time, average delivery rate, and fluency in target text production. Delivery time refers to the duration of target text production and fluency the smooth flow of target language rendition without interruptions or hesitations. Because of the orality of ST, target texts in ST may contain characteristics of disfluency, including pauses, false-starts and self-corrections. Fluency is one of the salient features of a professional interpreter's performance (Altman 1994: 36). Disfluency includes hesitations, corrections, false starts, repetitions, stuttering and slips of the tongue (Garnham 1985: 206). These hesitation markers may indicate processing difficulties or production difficulties. Hesitations may be marked by silent pauses and voiced pauses. Silent pauses are defined as "any interruption in the flow of speech which is manifested in silent form" (Marcias 2006: 28). Voiced pauses refer to fillers such as "uh" and "um."

TABLE 3

\section{Delivery Qualities}

\begin{tabular}{|c|c|c|c|c|c|c|c|c|}
\hline \multirow{2}{*}{$\begin{array}{l}\text { ID } \\
\text { S1 }\end{array}$} & \multicolumn{2}{|c|}{$\begin{array}{l}\text { Delivery time } \\
\text { (minutes) }\end{array}$} & \multirow{2}{*}{$\begin{array}{c}\begin{array}{c}\text { Target text } \\
\text { words } \\
\text { (in Korean) }\end{array} \\
627 \text { words }\end{array}$} & \multicolumn{2}{|c|}{$\begin{array}{l}\text { Average delivery } \\
\text { rate (words per } \\
\text { minute) }\end{array}$} & \multirow{2}{*}{$\begin{array}{c}\begin{array}{c}\text { Frequency of } \\
\text { long pause } \\
\text { (longest } \\
\text { pause) }\end{array} \\
6(4 \mathrm{sec})\end{array}$} & \multirow{2}{*}{$\begin{array}{c}\begin{array}{c}\text { Frequency } \\
\text { of voiced } \\
\text { pauses }\end{array} \\
20\end{array}$} & \multirow{2}{*}{$\begin{array}{c}\text { Repairs } \\
22\end{array}$} \\
\hline & 7.21 & \multirow{6}{*}{$\begin{array}{c}\text { average } \\
9.52\end{array}$} & & $87 \mathrm{wpm}$ & \multirow{6}{*}{$\begin{array}{c}\text { average } \\
70.63\end{array}$} & & & \\
\hline S2 & 11.11 & & 706 words & $63.5 \mathrm{wpm}$ & & $16(16 \mathrm{sec})$ & 59 & 22 \\
\hline S3 & 11.52 & & 679 words & $58.9 \mathrm{wpm}$ & & $26(14 \mathrm{sec})$ & 4 & 37 \\
\hline S4 & 9.42 & & 616 words & $65.4 \mathrm{wpm}$ & & $8(4 \mathrm{sec})$ & 23 & 39 \\
\hline S5 & 10.53 & & 709 words & $67.3 \mathrm{wpm}$ & & $14(8 \mathrm{sec})$ & 50 & 45 \\
\hline S6 & 7.31 & & 597 words & 81.7 wpm & & $6(4 \mathrm{sec})$ & 18 & 13 \\
\hline P1 & 7.43 & \multirow{3}{*}{$\begin{array}{c}\text { average } \\
7.15\end{array}$} & 673 words & $90.5 \mathrm{wpm}$ & \multirow{3}{*}{$\begin{array}{c}\text { average } \\
93.97\end{array}$} & $1(3 \mathrm{sec})$ & 40 & 27 \\
\hline P2 & 4.42 & & 470 words & $106.3 \mathrm{wpm}$ & & Nil & 6 & 11 \\
\hline P3 & 9.6 & & 817 words & $85.1 \mathrm{wpm}$ & & $11(5 \mathrm{sec})$ & 39 & 13 \\
\hline
\end{tabular}

Each subject's ST delivery time, average delivery rate, frequency of long pauses and duration of the longest pause are presented in Table 3 above. The delivery time was prolonged because of long pauses and frequent repairs. In this study, silent pauses exceeding two seconds were considered long pauses following Marcias (2006). The mean delivery time of the student and professional interpreters was 9.52 minutes and 7.15 minutes respectively. In the student group, S1 and S6 produced target texts relatively quickly, at 7.21 minutes and 7.31 minutes, which was even quicker than the delivery time of P1 and P3. The delivery time of S1 and S6 approached the average delivery time of the professional group. However, their target texts contained far more deviations in accuracy and target language expressions than the professional interpreters', which suggests that delivery time is not sufficient in itself for determining the quality of ST target texts (see the following sections for the discussion on accuracy and target language expressions). Slow delivery was largely due to a high frequency of long pauses, which will be discussed later. The delivery time of S2, S3, and S5 exceeded ten minutes. P2 was the only subject who finished a rendition within five minutes. The other professional interpreters' delivery took far longer than P2's. The delivery time of two professional interpreters (P1 and P3) ranked fourth and sixth 
in this study, with average delivery rates less than $100 \mathrm{wpm}$. Such variability amongst professionals of divergent backgrounds is not surprising given that inter-subject variability was a salient feature even in performances of professional conference interpreters of similar backgrounds in Lamberger-Felber's study (2003).

The average ST delivery rate examined in Moser-Mercer's study (1995) was markedly different between the student interpreter group and the professional interpreter group. Students' average delivery speed was about $60 \mathrm{wpm}$ while professional interpreters averaged $115 \mathrm{wpm}$ in her study. In this study, the rates were $70.63 \mathrm{wpm}$ and 93.97 wpm respectively. Except for S1 and S6, the speed of students' ST delivery stayed close to the beginner's mark set out in Moser-Mercer's study (1995). The gap between the two groups was smaller than the one in Moser-Mercer (1995).

As shown in Table 3, P2 was outstanding in delivery qualities, measured in terms of delivery time and fluency. P2 produced 470 words in Korean in 4.42 minutes, which equates to an average of 106 words per minute. ${ }^{5}$ None of her pauses exceeded two seconds. In addition to her speech rate, the condensation and omission strategies used by $\mathrm{P} 2$ contributed to quick delivery time and comprehensibility, which we will examine later in this paper. (See 2.3.5. for a discussion on the condensation strategy.)

In the professional interpreter group, P3 made frequent pauses (eleven times) whereas P1 made only one. In the student interpreter group, the number of students' long pauses varied between six and 26. Most of the subjects frequently used fillers such as "uh" and "um." These two were the most frequently used voiced pauses. As shown in Table 3, some used voiced pauses more frequently than silent pauses. For example, while P1 rarely paused silently, she frequently produced voiced pauses. P3 also produced fillers far more frequently than silent pauses. On the other hand, S3 rarely used voiced fillers, but she frequently used silent pauses. Such negative correlations between silent pauses and voiced pauses were also found in Mead (2000).

The data analysis indicates that repairs, including false-starts and self-corrections, were common in ST target texts. Repairs were found following pronunciation errors or slips of the tongue (e.g., towacwusil- towacwusikil ${ }^{6}$ [to help]). Repairs were made when the subjects added what they had omitted (e.g. uymisimcanghan mwullon kothongsulepciman uymisimcanghan senmwul [meaningful-painful but meaningful gift]). On occasion, repairs were found when interpreters made a false start and then rephrased the sentence by changing the subject (e.g., ceyka kotay yeyencaka hayssten [I- the ancient prophet did]). Repetition of utterances was also regarded as repairs (e.g., ceeykeynun maywu kahokhako e pwutanghan kesulo yekyecyessten e kulehan pwukoyesssupnita. e.. um.. kahokhako pwutanghan kesulo yekyecyessten kulehan pwukoyessupnita [it seemed to me a very harsh and uh unfair uh an obituary uh... um... a very harsh and unfair obituary]). Moreover, in this paper, stuttering is included in false starts, which might be related to the subject's anxiety or nervousness (e.g., ap-appak [pre-pressure]). (See Petite 2005 for repairs in SI.)

P2 made the fewest repairs and her target text contained the smallest number of false starts and self-corrections (a total of eleven repairs). S6 closely followed behind with 12 repairs. While P3's rendition was slow, she made relatively fewer self-corrections, recording 13 repairs. P1 frequently corrected her rendition (27 times), outnumbering repairs made by S1 and S2 (22 repairs). The other students, S3, S4, and S5, made frequent repairs. S3 and S4 corrected themselves 37 and 39 times respectively 
while S5 corrected herself most frequently, making 45 self-corrections for various reasons. Since this paper is based on ST only, it is not known how the frequency of repairs in ST compared with CI and SI.

\subsubsection{Accuracy}

In this paper the term accuracy refers to accurate reproduction in the target text of the source text message. Deviations from this quality of accuracy include omissions, additions and distortions/substitutions. In this paper, accuracy errors were divided into major errors and minor errors depending on the significance of the error and the degree of impact on the propositional meaning of the text. Minor errors included lexical choice problems and inadequate target language expressions that slightly changed the meaning of the source text.

TABLE 4

Accuracy Errors

\begin{tabular}{|c|c|c|c|c||c|c|c|c|}
\hline & \multicolumn{4}{|c||}{ Major errors (instances) } & \multicolumn{5}{c|}{ Minor errors (instances) } \\
\hline & R1 & R2 & R3 & Average & R1 & R2 & R3 & Average \\
\hline \hline S1 & 8 & 4 & 8 & 6.6 & 8 & 4 & 6 & 6 \\
\hline S2 & 8 & 3 & 6 & 5.7 & 6 & 4 & 1 & 3.7 \\
\hline S3 & 18 & 10 & 16 & 14.7 & 5 & 7 & 4 & 5.3 \\
\hline S4 & 12 & 4 & 8 & 8 & 4 & 6 & 1 & 3.7 \\
\hline S5 & 4 & 2 & 5 & 3.7 & 5 & 2 & 3 & 3.3 \\
\hline S6 & 14 & 7 & 17 & 12.7 & 1 & 8 & 3 & 4 \\
\hline P1 & 3 & 4 & 7 & 4.7 & 6 & 4 & 5 & 5 \\
\hline P2 & 1 & 0 & 4 & 1.7 & 8 & 3 & 6 & 5.7 \\
\hline P3 & 3 & 2 & 3 & 2.7 & 3 & 5 & 4 & 4 \\
\hline
\end{tabular}

For ease of comparison, the number of instances of major errors and minor errors are indicated in Table 4, along with the average. The number of mistranslated sentences itself may not be the sole indicator of the severity of mistranslation. The analysis of the target texts provided by the nine subjects revealed varying degrees of accuracy, and the results of the raters' assessment varied as shown above. Except for S5, student interpreters made far more major errors than professional interpreters. However, in terms of minor accuracies, there was no clear difference between the two groups. In the student group, S5 made relatively fewer major accuracy errors whereas S3 made the most major accuracy errors. While S6's delivery quality was good, her ST revealed numerous major accuracy errors. On average, in the professional group, P2 made fewer major accuracy errors. However, raters did not come up with exactly identical results in assessing accuracy. For example, Rater 2 found P2's ST free of major errors whereas Rater 3 found four major errors.

Sentences 21,22, and 24 turned out to be the most difficult sentences to translate given that most of the subjects failed to accurately translate these sentences, even the professionals. While professional interpreters' major accuracy errors were largely restricted to these challenging sentences, student interpreters' major errors were spread throughout the text. All subjects made errors in translating sentence 22 (see below), which is a quote of Winston Churchill's. The rhetorical feature and the linguistic paradox might have been difficult to translate naturally with little preparation. 
They go on in strange paradox, decided only to be undecided, resolved to be irresolute, adamant for drift, solid for fluidity, all powerful to be impotent.

Student interpreters' STs revealed that they did not understand the source language meaning and did not find equivalents which conveyed the intended message of this quotation. P2 did not provide a full translation, but used condensation strategy in interpreting sentence 22 . Her rendition, which is ituli wuyupwutanhako kyelcengul naylici moshamye sinnyemi mocalantako [they are ambivalent, irresolute and wavering] is considered acceptable since it does not hinder the coherence of the text and the communicative intent of the author, which may explain why the three raters did not find this problematic. Compared to the stilted target texts produced by other subjects, P2's condensed version is easier to understand. P2, the most experienced interpreter, successfully used the condensation strategy to handle rhetoric with little preparation. According to her feedback, condensation was a conscious choice to maintain the quality of delivery. This example challenges us to consider strategies in ST when the interpretability of the source text poses difficulty and adds to the processing effort of the interpreter. In addition, this raises the question of the feasibility of ST or sight translatability of complex and difficult texts. This is beyond the scope of this paper, but is worth scholarly investigation. Condensation strategy will be discussed later in a separate section.

\subsubsection{Target language quality}

ST target texts appear to share similar features to SI target texts in that they tend to be more surface-oriented compared to CI (Kohn and Kalina 1996: 119). Awkward target language expressions, including syntactic, lexico-grammatical and collocation problems, may partly be due to inter-language interference and the lack of bilingual skills. Agrifoglio (2004) refers to awkward target language expressions as "expression failures," which will be used interchangeably with target language errors in this paper.

TABLE 5

Target Language Expression Errors

\begin{tabular}{|c|c|c|c|c|}
\hline Subject & \multicolumn{5}{|c|}{ Number of target language errors } \\
\hline & R1 & R2 & R3 & Average \\
\hline \hline S1 & 7 & 24 & 18 & 16.3 \\
\hline S2 & 19 & 16 & 8 & 14.3 \\
\hline S3 & 20 & 34 & 18 & 24 \\
\hline S4 & 12 & 19 & 13 & 14.7 \\
\hline S5 & 9 & 14 & 13 & 12 \\
\hline S6 & 7 & 21 & 8 & 12 \\
\hline P1 & 6 & 11 & 6 & 7.7 \\
\hline P2 & 1 & 0 & 1 & 0.7 \\
\hline P3 & 3 & 11 & 8 & 7.3 \\
\hline
\end{tabular}

The three raters' assessment varied, but the average clearly indicates that the student interpreters' target texts contained more target language errors. Interpreters should keep monitoring their target text production for coherence and linguistic adequacy in ST and divide their efforts between reading and production. However, 
some students' ST revealed that they did not monitor the target language. In case of S2, it would have been necessary to add a clause ilwuki wihay [to achieve/serve] to indicate that the purpose is the objective case in this Korean rendition or it would have been acceptable to render it as mokcekul wihay [for this purpose] rather than mokcekun [the purpose is] in translating sentence 2. To take another example, S4 translated sentence 13 into cemyenghan kwahakcatul onul ceyka i sangul hamkkey kongtongulo swusanghakey toyessnunteyyo [respectable scientists today I have the honour of receiving awards together], which lacks a connective particle kwa following kwahakcatul [scientists]. Production problems such as mispronunciation and unfinished sentences were also found in the data. S5's target text includes an unfinished sentence kukesun ceyka cinan myech nyen tongan e ilwulyeko nolyekhaywassten kesip [this is what I've been trying to achieve over the past few years] which lacked the sentence ending particle -nita. Such production errors are made when the interpreters' efforts are not effectively allocated between monitoring their target language production and reading.

Many student interpreters produced awkward translations as a result of closely following the structure and style of the source text. Most of the expression failures were due to awkward collocation, grammatical and syntactical errors, and an oversight of cross-linguistic differences. For example, honourable exceptions in sentence 21 was literally translated by S1. The choice of adjective yengyeylowun [honourable] does not collocate with the noun yeyoytul [exceptions], nor does the expression make sense in the target language. Most of the interpreted renditions of this sentence were mistranslations which lacked logic and coherence, as mentioned above.

By comparison, the professional interpreters' expression problems did not cause logical problems. Moser-Mercer (1995) notes a striking difference in translation skills between student interpreters and professional interpreters, which she attributed to the professional interpreters' ability to analyse the source text faster and at deeper level, and to avoid being constrained by the source text form (Moser-Mercer 1995: 162). This study corroborates such a qualitative difference between the two groups. As shown above in Table 5, student interpreters produced far more literal translations than did the professional interpreters (see also McDonald and Carpenter 1981; Dragsted and Hansen 2007). This suggests, as Moser-Mercer (1995: 162) notes, that interpreting experiences may allow interpreters to free themselves from the constraints of the original. The professional interpreters' target language quality generally exceeded that of the student interpreters, and the assessment by the three raters confirmed P2 to be the best interpreter in this study. Her target text contained few target language errors as shown above. P1 and P3's expression problems were mostly related to lexical choices, such as using the source language dumping without translating it into Korean, and using phyeykimwul [waste] to describe greenhouse gas. Some minor syntactic errors were caused by disregard for subject and predicate agreement and following the sentence structure of the source language despite the fact that the inanimate subject in Korean may result in a somewhat unnatural rendition (Lee 2002: 65-66; Kim 2006: 51-52). 


\subsubsection{Condensation strategy}

This paper focuses mainly on one of the ST strategies, the condensation strategy, which can serve as an effective strategy to shorten delivery time and improve target text quality. ${ }^{7}$ Condensation is considered synonymous with "lexical and syntactic compression and omission" (Chernov 1994, cited by Pöchhacker 2004: 134) and "strategic information reduction" (Kirchhoff 2002: 116, cited by Pöchhacker 2004: 134). According to Kohn and Kalina (1996: 132), condensation is an "important overall rescue strategy" which enables the interpreter to present the target text at a faster rate and avoid excessive time lags. Condensation is possible when the interpreter processes the source text information at a higher macro level, leaving out redundant information and achieving a concise style in the target text. To condense the source text information, the interpreter may also choose linguistic simplification such as sentence splitting, paraphrasing or restructuring (Kohn and Kalina 1996: 132).

While omissions and additions in the ST target texts were rare in the present study, which may be due to the visual presence of the source text, the target texts often contained expression problems. Expression problems may have been caused by student interpreters' tendency to provide a complete and full translation, almost word for word, which is a time-consuming approach. Condensation strategies, which are based on the preservation of key ideas and restructuring, may improve ST performance through saving delivery time and achieving linguistic economy.

Since P2 was the only subject who used this strategy, extracts of P2's target texts were analysed in comparison with other subjects in order to demonstrate the effectiveness of condensation strategies. Given her extensive SI experience, P2 was assumed to have internalised this strategy. Translations of sentences 5 and 6 by S1 and $\mathrm{P} 2$ are presented below for comparison. The author's back-translation is provided immediately following the excerpts of the sight-translated texts, and the word counts are also indicated in brackets.

(1) One hundred and nineteen years ago, a wealthy inventor read his own obituary, mistakenly published years before his death. Wrongly believing the inventor had just died, a newspaper printed a harsh judgement of his life's work, unfairly labelling him "The Merchant of Death" because of his invention - dynamite. (48 words)

Interpretation by S1:

Payksipkwu nyen ceney acwu pwuyuhan palmyengkaka kuuy samangkisalul ilkkey toypnita. Bwuko- bwukolul ilkkey toynun kesiciyo. Kulen- kulentey i pwukopwukonun acwu calmos kicaytoyn kesulose kuka cwukki a myech nyen ceney naon kesipnita. Kuliko e i sinmwunsaeysenun amato i palmyengkaka cwukesstalako calmos sayngkakhako issessupnita. I sinmwuneysenun acwu kahokhan etten phyengkyelul naylyessnuntey e ku phyengkyelun acwu pwulkongphyenghan kesi pwu- pwulkongphyenghayse ku ku pwuyuhan palmyengkalul cwukumuy sanginilako phohyenhayssupnita. Waynyahamyen kuka palmyenghan tainamaithu ttaymwunipnita. (69 words)

[119 years ago, a very rich inventor read his obituary. He read an obituary- obituary. An- And this obituary- obituary was severely inaccurate and it came out years before he died. And uh this newspaper mistakenly thought this inventor had passed away. This newspaper gave him a very harsh uh verdict. This verdict was very unfair, un-unfair and called the the rich inventor the merchant of death. It was because of his invention, dynamite.] 
Interpretation by $\mathrm{P} 2$ :

Payksipkwu nyen ceney etten palmyengkaka casiney tayhan pwukolul ilkesstako hapnita. Kuka cwukci anhassumeyto sinmwuney nawassten pwukonun- i pwukonun- palmyengkaey tayhan ku iyakinun kuey tayhan pwutanghan kulen phyengkayesssupnita. Casini palmyenghan tainamaithu ttaymwuney kulul cwukumul phanun sanginulo myosahayssten pwukoyesssupnita. (37 words)

[119 years ago, uh an inventor is said to have read his own obituary. His obituary, published in the newspaper even though he did not pass away, was an unfair judgement about him. This was an obituary that described him as 'the merchant of death' because of his invention, dynamite.]

A comparison of the target texts revealed that S1 translated every word and phrase in the source text, without condensing the text effectively. For example, while P2 concisely translated the reason behind such a harsh judgment of the inventor, S1 treated because of his life's work - dynamite as a separate sentence in the target text. S1 also translated the clauses mistakenly published in the newspaper and wrongly believing the inventor had just died as separate sentences. Since S1 divided a sentence in the source text into two without abridging by means of conjunctions, the target text was slightly lengthened (see the word count). With repeated formal sentence ending forms -nita, the Korean output sounded somewhat repetitive and fragmented.

Segmentation can relieve the simultaneous interpreter's memory efforts but may involve higher processing capacity, increasing production effort (Gile 1995: 195-196). S1's excessive sentence segmentation might have been related to production problems. While proficient interpreters may be competent in reformulating the original message concisely and naturally in the target language, student interpreters like S1 may not have mastered such a skill. Alternatively, S1's excessive segmentation and inefficient target text production may have been related to his reading span and memory capacity. If he had been able to scan the incoming information or hold the preceding source text information while reading the next bit of information, he might have chosen translation units differently. However, the current research method did not allow the researcher to investigate the cause further.

P2's translation indicates that she treated mistakenly published in the newspaper and wrongly believing the inventor had just died, a newspaper and harsh judgement and unfairly labelling as repeated and thus redundant information. In addition, she focused on more important information and omitted ancillary information such as years prior to his death and merely translated that it was published before his death. P2 also omitted wealthy and translated $a$ wealthy inventor into an inventor. The second sentence in P2's ST above Kuka cwukci anhassumeyto sinmwuney nawassten pwukonun- i pwukonun- palmyengkaey tayhan ku iyakinun kuey tayhan pwutanghan kulen phyengkayesssupnita [His obituary, published in the newspaper even though he did not pass away, was an unfair judgement about him] is a condensed version of the source text mistakenly published years before his death. Wrongly believing the inventor had just died, a newspaper printed a harsh judgement of his life's work. The impact of such information loss may be minimal, and it should be noted that not all omissions are indicators of lesser quality.

Let us examine another extract from P2's target text in comparison with another professional interpreter's target text. The following extracts are translations of sentences 9 and 10 of the source text. 
(2) Seven years ago tomorrow, I read my own political obituary in a judgement that seemed to me harsh and mistaken - if not premature. But that unwelcome verdict also brought a precious if painful gift: an opportunity to search for fresh new ways to serve my purpose.

Interpretation by $\mathrm{P} 2$ :

Chil nyen ceney palo ceto kuwa pisushan kyenghemul hayesssupnita. Nauy cengchisayngmyeni kkuthnasstanun kulehan e iyakituli manhi issessko kuttayeynun ceto ikesey tayhase sangtanghi manhun chwungkyekul patasssupnitamanun kulayse ohiley cenhwawipokuy kyeykika toyessko cenun saylowun pangpepulo inlyuey konghenhakoca nolyekul hakey toyessupnita. (37 words)

[Seven years ago, I also had a similar experience. There was a lot of talk about the end of my political career. I was quite shaken by this at the time, but it was a blessing in disguise, and I have tried to serve the humankind in a new way.]

Interpretation by P3:

E nalccalo chicamyen nayil nalccainteyyo. Cek nayil nalccalopwuthe chil nyen ceney ceto ce casinuy etten cengchicekin epcekey e ey kwanhan kulul ilhkey toyesssupnita. Kulentey ceyka pokiey ku kulilako hanun kesun cokum piphanuy kangtoka kanghako kuliko tto ohayuy socika issnun kuliessko tto eccemyen ceey tayhayse phantanul naylikieynun cokum sikisangcouy sengkyekul ttiko issnun kulilako sayngkaki toyesssupnita. Kulehciman iwa kathun ce casineykeynun kulehkey pankilman hacinun anhassciman i kulul thonghayse naylyecin ku phyengkyel hokum phantanul thonghayse cenun e koycanghi kothongsulepciman socwunghan senmwulul kackey toyesssupnita. I senmwulilako hanun kesi palo ceuy mokcekul i sayngeyse ilwuki wihan saylowun panganul ceyka mosaykhal swu issnun kihoylul pwuyepatasstanun kesipnita. (98 words)

[Uh, to be exact, it's tomorrow's date. Seven years ago tomorrow I also read what was written about my political achievement. But in my opinion, it was a bit harsh and it might cause misunderstanding, and it seemed to me that it delivered a somewhat premature judgement on me. However, this- it was not pleasant to me, but through the verdict or judgement delivered by this writing, I received a very painful, but precious gift. This gift was none other than the opportunity I was given to search for a new way to fulfil my mission in this life.]

P2's text length is less than a half of P3's (37 words versus 98 words). P3's target text is a complete and full translation of the source text, which reveals that she tried to render the source text completely. As a result, her rendition turned out to be very wordy. P2's target text is a free translation based on the meaning. It is a condensed version, which effectively conveys the meaning of the source text and facilitates the audience's understanding. Although she omitted harsh and mistaken - if not premature, she effectively dealt with a metaphor of political obituary in the target language rendition by choosing an idiomatic and natural target language expression. In a sense, she sacrificed some details of little significance to enhance delivery. For example, instead of faithfully translating seven years ago tomorrow, P2 rendered simply into seven years ago in Korean. P2's target text suggests that she could analyse the source text quickly and understand the overall structure of the source text. Her omissions did not compromise the coherence or the communicative aim of the text.

Accuracy generally implies faithful and complete reproduction of original messages or "informational correspondence" (Pöchhacker 2004: 141). However, source text-target text correspondence is secondary to the communication function of the target text (Donovan-Cagigos 1990: 400, cited by Pöchhacker 2004: 143). The question 
of justifiable omission is related to context (Pym 2008: 88). In certain contexts, such as in legal proceedings where accuracy is vital, the interpreter should refrain from providing a condensed version of the source text in ST. In most conference interpreting settings, where this type of speech is delivered, the interpreter may condense information to convey the original message for efficient and effective message delivery. The absence of condensation in eight of the nine subjects' outputs may have been related to the fact that this experimental study lacked the socio-cultural context in which the work of the interpreter is grounded. More importantly, however, the nonuse of condensation strategy by both students and professionals (except P2) may indicate their lack of experience in conference interpreting and insufficient mastery of such a vital skill. Since conciseness is expected in interpreting outputs, student interpreters need to be alerted to the negative consequence of excessive sentence segmentation and they need to learn the condensation strategy through training.

\subsubsection{Self-assessment and marking}

In order to investigate the subjects' awareness of their own ST quality, self-assessments of their own performances were sought. They were asked to highlight the areas where they had had problems in ST comprehension and target language renditions. They were also asked to rank their performance using a five-point scale ranging from very poor to very good. Two student interpreters (S4, S6) chose neutral while three (S1, S2, S5) chose poor and S3 chose very poor. P1 chose neutral and P3 chose good, whereas P2 chose poor. The lack of correlation with true performance indicates that self-rating is subjective, which may not match the reality.

The professionals highlighted challenging parts of the text, which mostly covered the problems found in their translated outputs, but student interpreters did not highlight many of the problems identified by the raters. This discrepancy was particularly noticeable in relation to target language quality errors. This suggests that the student interpreters might not have been fully aware of the quality aspects of their performance and that they may need more guidance and teachers' input in developing translation skills. This lack of awareness is an interesting research issue, which can be invested in future research.

As for markings in the reading stage, the subjects behaved differently. Five subjects marked translation units with slashes (S1, S2, S4, P2, and P3). They circled some words and wrote down translation equivalents or ideas. This shows that a kind of pre-translation was going on during the reading stage. S3, S5, and S6 underlined a few words and wrote down translations of some words, but P1 did not leave any marks on the source text. It is generally viewed that effective marking can facilitate renditions, so students are encouraged to mark meaning units, the order of translating, or important information. However, the results did not yield conclusive evidence about the benefits of marking, and it was impossible to investigate how marking influenced the ST renditions in this study design.

\section{Conclusions}

Drawing on the analysis of ST performances of student interpreters and professional interpreters, this paper has examined qualitative differences in these two groups' performances in terms of reading, delivery, accuracy and target language quality. 
Inter-subject variability in ST outputs was clearly observed in both groups in this study. Most student interpreters' performances generally fell short of the professional interpreters' in the areas of reading, accuracy and target language quality, but in areas like delivery qualities, some student interpreters outperformed professional interpreters in terms of delivery time and the frequency of pauses. P2 was considered the only subject that exhibited expert performance in all aspects examined here. However, the professional interpreters, as a group, outperformed student interpreters in reading speed, delivery time and average delivery rate. They made fewer major accuracy errors, and their target language problems were limited to minor lexical or syntactic errors. By comparison, the student interpreters' target language errors revealed that they could not coordinate reading and oral production. Their target language errors may also have resulted from their lack of proficiency in translation skills and avoiding interference of the source text linguistic forms.

Notably, most student interpreters could not finish reading the source text within the limited reading time, which may have influenced their ST performance. It is suspected that the students' incomplete reading, caused by slow reading speed, and inadequate comprehension might have led to inaccuracies in target texts. In that sense, reading exercises that strengthen their text analysis ability are needed in order to reinforce their ST skill development.

Apart from reading, the students' long delivery time and their verbose target texts may be attributable to their tendency to faithfully translate every word, and inability to preserve key ideas and condense information without compromising the meaning of the source text. These findings suggest that student interpreters need more training to enhance their translation skills, which include segmenting translation units and condensing the source text information effectively, and thereby improve their time efficient delivery. Students need to be sensitised to the problem of awkward target language expressions and prolonged delivery time in ST. It is argued that the condensation strategy can serve as an important skill enabling the interpreter to shorten the delivery time and avoid wordy, often awkward, target language expressions.

This paper did not find any meaningful connection between preparation, such as marking and preparatory translation, and ST performance, and calls for further research to investigate how different preparation activities affect ST performance. More research is needed to develop ST teaching methods so that teachers can help students to achieve professional proficiency. Just telling student interpreters to read quickly and practise more may be of no avail, and we need an effective pedagogical tool to enhance student interpreters' ST performances. Given that the student interpreters did not highlight all the problem areas on the source text, which suggests that they might not have realized their errors in accurate message delivery and target language expressions, they may benefit from more rigorous and detailed feedback based on ST performance analysis.

Despite its limitations, this pilot study has sought to examine ST skills and proficiency, which have received little attention from a didactic perspective. Follow-up research is required to further explore ST processes and strategies capable of being applied in ST training. Studies in reading and speaking and a psycholinguistic approach towards translation and interpreting may be useful for us to examine this complex process of ST. 


\section{NOTES}

1. Skills and strategies are sometimes used interchangeably in reference to a wide range of processing tasks, behaviours and abilities (Koda 2005: 209). Skills are used subconsciously while strategies require deliberate activation and conscious decisions (Paris, Wasik et al. 1991; Koda 2005: 210). According to Cohen (1990: 83), a skill is an overall heavior while a strategy is the specific means for realising that behaviour.

2. Such findings suggest that Gile's (1995: 169) Efforts Model in ST should include Reading, Shortterm Memory, Production and Coordination. ST is based on reading and target text production, which requires memory and coordination of the interpreter. (See Shreve, Lacruz et al. 2010: 66's modified model for ST).

3. Each sentence is numbered in this source text for ease of data presentation in this paper.

4. Given that interpreters may not always have sufficient preparation time, six minutes, equivalent to a reading rate of approximately $100 \mathrm{wpm}$, was considered as the appropriate reading time for this research. It was expected that semi-rehearsed ST, with limited reading time, might reveal differences between professional interpreters' and student interpreters' performances.

5. According to Nickerson (1981: 273), average English speakers speak at a rate of between 125 words and 175 words per minute. Individual speech rate and performance style differences may explain individual differences. P2 commented that she was conscious of the need in actual conference interpreting settings that the interpreter has to speak rapidly to keep pace with the speaker. P3 commented that she focused more on accurate rendition than on delivery time. Such different orientations may influence the quality of ST performances.

6. The Korean transcriptions use the Yale Romanisation system.

7. See Alexieva (1983), Dam (1993), and Sunnari (1995) for processing strategies in SI and CI.

\section{REFERENCES}

Agrifoglio, Marjorie (2004): Sight translation and interpreting: A comparative analysis of constraints and failures. Interpreting. 6(1):43-67.

Alexieva, Bistra (1983): Compression as a means of realisation of the communicative act in simultaneous interpreting. Fremdsprachen. 27(4):233-238.

Altman, Janet (1994): Error analysis in the teaching of simultaneous interpretation: A pilot study. In: Sylvie Lambert and Barbara Moser-Mercer, eds. Bridging the Gap: Empirical research on simultaneous interpretation. Amsterdam/Philadelphia: John Benjamins, 25-38.

Angelelli, Claudia (1999): The role of reading in sight translation. The ATA Chronicle (Translation Journal of the American Association of Translators). 28(5):27-30.

BLOCK, Ellen (1992): See how they read: Comprehension monitoring of L1 and L2 readers. Tesol Quarterly. 26(2):319-343.

Brady, M. (1989): Case studies in sight translation. In: John M. Dodds, ed. Aspects of English: Miscellaneous papers for English teachers and specialists. Udine: Campanotto Editore, 141-183.

Carrell, Patricia. L. (1989): Metacognitive awareness and second language reading. Modern Language Journal. 73(2):121-133.

Chernov, Ghelly V. (1994): Message redundancy and message anticipation in simultaneous interpretation. In: Sylvia Lambert and Barbara Moser-Mercer, eds. Bridging the Gap: Empirical research in simultaneous interpretation. Amsterdam: John Benjamins, 139-153.

CoHen, Andrew D. (1990): Language Learning: Insights for Learners, Teachers, and Researchers. Boston: Heinle \& Heinle.

DAM, Helle V. (1993): Text condensing in consecutive interpreting. In: Yves Gambier and Jorma Tommola, eds. Translating and Knowledge: SSOTT IV. Turku: University of Turku, 297-313.

DAvis, James N. and BistodeAu, Linda (1993): How do L1 and L2 reading differ? Evidence from think aloud protocols. The Modern Language Journal. 77(4):459-472.

Donovan-Cagigos, Clare (1990): La fidélité en interprétation. Doctoral dissertation, unpublished. Paris: Université de la Sorbonne Nouvelle - Paris 3.

Dragsted, Barbara and Hansen, Inge G. (2007): Speaking your translation: Exploiting synergies between translation and interpreting. In: Franz PöchнACкer, Arnt L. JAKobSEN and 
Inger M. MeEs, eds. Interpreting Studies and Beyond. Copenhagen Studies in Language 35. Frederiksberg: Samfundslitteratur Press, 251-274.

Garnham, Alan (1985): Psycholinguistics: Central Topics. London/New York: Routledge.

GILE, Daniel (1994): Methodological aspects of interpretation and translation research. In: Sylvie Lambert and Barbara Moser-Mercer, eds. Bridging the Gap: Empirical Research in Simultaneous Interpretation. Amsterdam/Philadelphia: John Benjamins, 39-56.

GiLe, Daniel (1995): Basic Concepts and Models for Interpreter and Translator Training. Amsterdam/ Philadelphia: John Benjamins.

ILG, Gerard and LAMBERT, Sylvie (1996): Teaching consecutive interpreting. Interpreting. 1(1):6999.

Ivars, Amparo Jiménez (2008): Sight translation and written translation. A comparative analysis of causes of problems, strategies and translation errors within the PACTE translation competence model. Forum. 6(2):79-103.

Jakobsen, Arnt L. and Jensen, Kristian T. H. (2008): Eye movement behaviour across four different types of reading task. In: Susanne Göpferich, Arnt L. Ja KobSEN and Inger M. Mees, eds. Looking at Eyes: Eye-Tracking Studies of Reading and Translation Processing. Copenhagen: Samfundslitteratur, 103-124.

KIM, Jong-woo (2006): Yengepenyek ATOZ [English Translation from A to Z]. Seoul: Dongyang Books.

KodA, Keiko (2005): Insights into Second Language Reading: A Cross-linguistic Approach. Cambridge: Cambridge University Press.

KirchHoff, Hella (1976/2002): Simultaneous interpreting: Interdependence of variables in the interpreting process, interpreting models and interpreting strategies. In: Franz $\mathrm{PöcH}-$ HACKER and Miriam SCHLEsinger, eds. The interpreting studies reader. London and New York: Routledge, 111-119.

KoHn, Kurt and Kalina, Sylvia (1996): The strategic dimension of interpreting. Meta. 41(1):118138.

Lamberger-Felber, Heiker (2003): Performance variability among conference interpreters: Examples from a case study. In: Angela Collados Aís, Manuela Fernández Sánchez and Daniel Gile, eds. La Evaluación de La Calidad en Interpretación: Investigación. Granada: Comares, 147-168.

LAMBert, Sylvie (2004): Shared attention during sight translation, sight interpretation and simultaneous interpretation. Meta. 49(2):294-306.

LEE, Jieun (2008): Rating scales for interpreting performance assessment. The Interpreter and Translator Trainer. 2(2):165-184.

LeE, Young-ok (2002): Hankwukewa yengekan enekwuco chaiey ttalun penyekuy mwuncey [Translation problems between Korean and English reflecting their structural differences: with respect to the translation of reported speech]. Penyekhakyenkwu [Translation Studies]. 3(1):59-81.

Liv, Minhua (2008): How do experts interpret?: Implications from research in Interpreting Studies and cognitive science. In: Gyde Hansen, Andrew Chesterman and Heidrun Gerzymisch-Arbogast, eds. Efforts and Models in Interpreting and Translation Research. Amsterdam/Philadelphia: John Benjamins, 161-177.

Liu, Minhua, Shallert, Diane L. and Carroll, Patrick J. (2004): Working memory and expertise in simultaneous interpreting. Interpreting. 6(1):19-42.

Marcias, Macarena P. (2006): Probing quality criteria in simultaneous interpreting. Interpreting. 8(1):25-43.

Martin, Ann (1993): Teaching sight translation to future interpreters. In: Catriona Picken, ed., Translation: The Vital Link. (13 ${ }^{\text {th }}$ World Congress of FIT, Brighton, 6-13 August 1993) London: Institute of Translation and Interpreting, 398-405.

McDonald, Janet and Carpenter, Patricia A. (1981): Simultaneous translation: Idiom interpretation and parsing heuristics. Journal of Verbal Learning and Verbal Behaviour. 20(2):231247. 
MEAD, Peter (2000): Control of pauses by trainee interpreters in their A and B languages. The Interpreters' Newsletter. 10:88-102.

Miller, Paul W. (2005): Reading comprehension, vocabulary and background knowledge: A case study. In: Jan Engberg, Marianne G. Ditlevsen, Peter Kastberg, et al., eds. New Directions in LSP Teaching. Bern: Peter Lang, 141-161.

Moser-Mercer, Barbara (1995): Sight translation and human information processing. In: Albrecht Neubert, Gregory Shreve and Klaus Gommlich, eds. Basic Issues in Translation Studies. Kent: Kent State University, 159-166.

Moser-Mercer, Barbara (1997): The expert-novice paradigm in interpreting research. In: Eberhard Fleischmann, Wladimir Kutz and Peter Axel Schmitt, eds. Translationdidaktik. Tubingen: Gunter Narr, 255-261.

Nickerson, Raymond S. (1981): Speech understanding and reading: Some differences and similarities. In: Ovid J. L. Tzeng and Harry Singer, eds. From Perception of Print: Reading Research in Experimental Psychology. Hillsdale: Lawrence Erlbaum Associates, 257-289.

Paris, Scott G., WAsik, Barbara A. and Turner, Julian C. (1991): The development of strategic reading. In: Rebecca BARR, Michael. L. KAmiL, P. B. Mosenthal, et al., eds. Handbook of Reading Research. New York: Longman, 609-640.

Petite, Christelle (2005): Evidence of repair mechanisms in simultaneous interpreting: A corpus-based analysis. Interpreting. 7(1):27-49.

PöchHACKer, Franz (2004): Introducing Interpreting Studies. London: Routledge.

Рyм, Anthony (2008): On omission in simultaneous interpreting: Risk analysis of a hidden effort. In: Gyde Hansen, Andrew Chesterman and Heidrun Gerzymisch-Arbogast, eds. Efforts and Models in Interpreting and Translation Research. Amsterdam/Philadelphia: John Benjamins, 83-105.

Pyм, Anthony (2009). Translator training. Visited 1 September 2010, <http://www.tinet.cat/ $\sim$ apym/on-line/training/2009_translator_training.pdf $>$.

Shreve, Gregory M., LaCruz, Isabel and Angelone, Erik (2010): Cognitive effort, syntactic disruption, and visual interference in a sight translation task. In: Gregory M. SHREve and Erik Angelone, eds. Translation and Cognition. Amsterdam/Philadelphia: John Benjamins, 53-84.

STANOvich, Keith E. (1980): Toward an interactive - Compensatory model of individual differences in the development of reading fluency. Reading Research Quarterly. 16(1):32-71.

SunNaRI, Marianna (1995): Processing strategies in simultaneous interpreting: 'Saying It all' vs. synthesis.' In: Jan Tommola, ed. Topics in Interpreting Research. Turku: University of Turku, 109-119.

VIAGgio, Sergio (1995): The praise of sight translation (and squeezing the last drop thereout of). The Interpreters' Newsletter. 6:33-42.

VIEZzI, Maurizio (1989): Information retention as a parameter for the comparison of sight translation and simultaneous interpretation: An experimental study. The Interpreters' Newsletter. 2:65-69.

VIEZZI, Maurizio (1990): Sight translation, simultaneous interpretation and information retention. In: Laura Gran and Christopher TAYLOR, eds. Aspects of Applied and Experimental Research on Conference Interpretation. Udine: Campanatto Editore, 54-60.

WEBER, Wilhelm K. (1990): The importance of sight translation in an interpreter training program. In: David Bowen and Margaret Bowen, eds. Interpreting - Yesterday, Today and Tomorrow. New York: Binghamton, 44-52.

\section{APPENDIX}

\section{Source text excerpt for analysis}

1 I have a purpose here today.

2 It is a purpose I have tried to serve for many years. 
3 I have prayed that God would show me a way to accomplish it.

4 Sometimes, without warning, the future knocks on our door with a precious and painful vision of what might be.

5 One hundred and nineteen years ago, a wealthy inventor read his own obituary, mistakenly published years before his death.

6 Wrongly believing the inventor had just died, a newspaper printed a harsh judgement of his life's work, unfairly labelling him "The Merchant of Death" because of his invention dynamite.

7 Shaken by this condemnation, the inventor made a fateful choice to serve the cause of peace.

8 Seven years later, Alfred Nobel created this prize and the others that bear his name.

9 Seven years ago tomorrow, I read my own political obituary in a judgement that seemed to me harsh and mistaken - if not premature.

10 But that unwelcome verdict also brought a precious if painful gift: an opportunity to search for fresh new ways to serve my purpose.

11 Unexpectedly, that quest has brought me here.

12 Even though I fear my words cannot match this moment, I pray what I am feeling in my heart will be communicated clearly enough that those who hear me will say, "We must act."

13 The distinguished scientists with whom it is the greatest honour of my life to share this award have laid before us a choice between two different futures

14 - a choice that to my ears echoes the words of an ancient prophet:

15 "Life or death, blessings or curses.

16 Therefore, choose life, that both thou and thy seed may live."

17 We, the human species, are confronting a planetary emergency

18 - a threat to the survival of our civilization that is gathering ominous and destructive potential even as we gather here.

19 But there is hopeful news as well:

20 we have the ability to solve this crisis and avoid the worst - though not all - of its consequences, if we act boldly, decisively and quickly.

21 However, despite a growing number of honourable exceptions, too many of the world's leaders are still best described in the words Winston Churchill applied to those who ignored Adolf Hitler's threat:

22 "They go on in strange paradox, decided only to be undecided, resolved to be irresolute, adamant for drift, solid for fluidity, all powerful to be impotent."

23 So today, we dumped another 70 million tons of global-warming pollution into the thin shell of atmosphere surrounding our planet, as if it were an open sewer.

24 And tomorrow, we will dump a slightly larger amount, with the cumulative concentrations now trapping more and more heat from the sun.

25 As a result, the earth has a fever.

26 And the fever is rising.

27 The experts have told us it is not a passing affliction that will heal by itself.

28 We asked for a second opinion.

29 And a third.

30 And a fourth.

31 And the consistent conclusion, restated with increasing alarm, is that something basic is wrong.

32 We are what is wrong, and we must make it right.

33 Last September 21, as the Northern Hemisphere tilted away from the sun, scientists reported with unprecedented distress that the North Polar ice cap is "falling off a cliff."

34 One study estimated that it could be completely gone during summer in less than 22 years.

35 Another new study, to be presented by U.S. Navy researchers later this week, warns it could happen in as little as 7 years.

36 Seven years from now. 